\title{
Global Stability for a Asymptotically Periodic Cooperative Lotka-Volterra System with Time Delays
}

\author{
Talat Tayir, Rouzimaimaiti Mahemuti \\ College of Mathematics and System Sciences, Xinjiang University, Urumqi, China \\ Email: ruzzi_257@163.com
}

How to cite this paper: Tayir, T. and Mahemuti, R. (2017) Global Stability for a Asymptotically Periodic Cooperative LotkaVolterra System with Time Delays. Open Journal of Applied Sciences, 7, 207-212. https://doi.org/10.4236/ojapps.2017.75018

Received: March 20, 2017

Accepted: May 28, 2017

Published: May 31, 2017

Copyright $\odot 2017$ by authors and Scientific Research Publishing Inc. This work is licensed under the Creative Commons Attribution International License (CC BY 4.0).

http://creativecommons.org/licenses/by/4.0/

\begin{abstract}
In this paper a class of cooperative Lotka-Volterra population system with time delay is considered. Some sufficient conditions on the existence and globally asymptotically stability for the asymptotically periodic solution of the system are established by using the Lyapunov function method and the method given in Fengying Wei and Wang Ke (Applied Mathematics and Computation 182 (2006) 161-165).
\end{abstract}

\section{Keywords}

Lotka-Volterra Cooperative System, Asymptotically Periodic Function, Global Asymptotic Stability, Time Delay

\section{Introduction}

Since Lotka-Volterra system has been established and was accepted by many scientists, it becomes the most important means to explain the ecological phenomenon now. For many years, a lot of extensive research results were made in mathematical biology and mathematical ecology [1]-[8], during this time LotkaVolterra system has played an important role in theses research field of mathematical biology and mathematical ecology. Still now many research work mostly discussed periodic Lotka-Volterra systems [2] [3] [4] [5] [6] and the references cited therein. In fact asymptotically periodic systems [3] [4] describe our world more realistic and more accurate than periodic ones.

As is well known, Lotka-Volterra Cooperative system is one of the most important classe of interaction model which is discussed widely in mathematical biology and mathematical ecology.

In this paper we consider the following Lotka-Volterra cooperative system with time delay: 


$$
\left\{\begin{array}{l}
\dot{x}_{1}(t)=x_{1}(t)\left[r_{1}(t)-a_{11}^{1}(t) x_{1}(t-\tau)-a_{11}^{2}(t) x_{1}(t-2 \tau)+a_{12}^{1}(t) x_{2}(t-\tau)\right] \\
\dot{x}_{2}(t)=x_{2}(t)\left[r_{2}(t)+a_{21}^{0}(t) x_{1}(t)+a_{21}^{1}(t) x_{1}(t-\tau)-a_{22}^{0}(t) x_{2}(t)-a_{22}^{1}(t) x_{2}(t-\tau)\right]
\end{array}\right.
$$

where $x_{1}(t), x_{2}(t)$ are the density of two cooperative species at time $t$ respectively, $r_{i}(t)(i=1,2)$ are intrinsic growth rate of two cooperative species at time $t$ respectively, $a_{11}^{l}(t)(l=1,2), \quad a_{22}^{l}(t)(l=0,1)$ are the intra patch restriction density of species $x_{1}, x_{2}$, at time $t$ respectively, and $a_{21}^{l}(t)(l=0,1), a_{12}^{1}(t)$ are the are cooperative coefficients between two species at time $t$ respectively. In this paper we assume that system (1) satisfies the following assumption

(H1) $\tau$ is a positive constant and $r_{i}(t)(i=1,2), \quad a_{11}^{l}(t)(l=1,2)$, $a_{22}^{l}(t)(l=0,1), \quad a_{21}^{l}(t)(l=0,1)$ and $a_{21}^{1}(t)$ are continuous, asymptotically periodic, bounded and strictly positive functions on $[-\tau,+\infty)$.

From the viewpoint of mathematical biology, in this paper, for system (1) we consider the solution with the following initial condition

$$
\begin{aligned}
& x_{1}(t)=\phi_{1}(t) \geq 0, \quad \text { for } t \in[-2 \tau, 0] \text { and } \phi_{1}(0)>0, \\
& x_{2}(t)=\phi_{2}(t) \geq 0 \text { for } t \in[-\tau, 0] \text { and } \phi_{2}(0)>0
\end{aligned}
$$

then for any $\left(t_{0}, \phi\right), \phi \in C=C\left((-2 \tau, 0], R_{+}^{n}\right)$, System (1) with initial conditions has a unique solution denoted by $X\left(t, t_{0}, \phi\right)$.

For a continuous and bounded function $f(t)$, we define

$$
f^{L}=\inf _{t \in[0,+\infty]}\{f(t)\} \text { and } f^{M}=\sup _{t \in[0,+\infty]}\{f(t)\}
$$

Y. Nakata and Y. Muroya have proved in [1] that the system (1) is permanent under the following conditions

$$
b_{1}^{L L}>0(l=1,2), b_{2}^{L L}>0 \text { and } b_{22}^{L L}>0
$$

where

$$
b_{1}^{l}(t)=a_{11}^{l}-a_{21}^{l-1}(t-\tau) \text { for } l=1,2 \text { and } b_{2}^{1}(t)=a_{22}^{0}(t-\tau)-a_{21}^{1}(t)
$$

which means that the system (1) had a bounded region that is

$$
\Phi=\left\{\left(x_{1}(t), x_{2}(t)\right): 0<m_{i} \leq x_{i}(t) \leq M_{i}(t) \leq+\infty(i=1,2)\right\}
$$

In particularly,

$$
\begin{gathered}
M_{1}=-\frac{a_{12}^{1 M} P}{r_{1}^{M}}+\left\{\frac{a_{12}^{1 M} P}{r_{1}^{M}}+x^{*}\right\} \exp \left(r_{1}^{M} 2 \tau\right) \\
M_{2}=\frac{r_{2}^{M}+\left(a_{21}^{0 M}+a_{21}^{1 M}\right) M_{1}}{a_{22}^{0 L}+a_{22}^{1 L}} \exp \left\{\left(r_{2}^{M}+\left(a_{21}^{0 M}+a_{21}^{1 M}\right) M_{1}\right) \tau\right\} \\
m_{1}=\frac{r_{1}^{L}}{a_{11}^{1 M}+a_{11}^{2 M}} \exp \left\{\left(r_{1}^{L}-\left(a_{11}^{1 M}+a_{11}^{2 M}\right) M_{1}\right) 2 \tau\right\} \\
m_{2}=\frac{r_{2}^{L}}{a_{22}^{0 M}+a_{22}^{1 M}} \exp \left\{\left(r_{2}^{L}-\left(a_{22}^{0 M}+a_{22}^{1 M}\right) M_{2}\right) \tau\right\}
\end{gathered}
$$

where $x=x_{1}^{*}$ is the unique positive solution of $x\left(r_{1}^{M}-\left(a_{11}^{1 L}+a_{11}^{2 L}\right) x\right)+a_{12}^{1 M} P=0$, and $\mathrm{p}$ is a positive constant such that, 


$$
\lim _{t \rightarrow+\infty} \sup x_{1}(t) x_{2}(t-\tau) \leq P=\frac{\left(r_{1}^{M}+r_{2}^{M}\right)^{2}}{b_{1}^{1 L} a_{22}^{1 L}} \exp \left\{\left(r_{1}^{M}+r_{2}^{M}\right) \tau\right\}<+\infty
$$

Let the set

$$
\Gamma=\left\{\left(x_{1}(t), x_{2}(t)\right) \in R_{+}^{2}: 0<m_{i} \leq M_{i}(t)<+\infty(i=1,2), R_{+}=[0,+\infty)\right\}
$$

where $m_{i}, M_{i}(i=1,2)$ are given above, then set $\Gamma$ is the ultimately bounded set of system (1)

Following is the adjoin system (2) of system (1)

$$
\left\{\begin{array}{l}
\dot{x}_{1}(t)=x_{1}(t)\left[r_{1}(t)-a_{11}^{1}(t) x_{1}(t-\tau)-a_{11}^{2}(t) x_{1}(t-2 \tau)+a_{12}^{1}(t) x_{2}(t-\tau)\right] \\
\dot{x}_{2}(t)=x_{2}(t)\left[r_{2}(t)+a_{21}^{0}(t) x_{1}(t)+a_{21}^{1}(t) x_{1}(t-\tau)-a_{22}^{0}(t) x_{2}(t)-a_{22}^{1}(t) x_{2}(t-\tau)\right] \\
\dot{y}_{1}(t)=y_{1}(t)\left[r_{1}(t)-a_{11}^{1}(t) y_{1}(t-\tau)-a_{11}^{2}(t) y_{1}(t-2 \tau)+a_{12}^{1}(t) y_{2}(t-\tau)\right] \\
\dot{y}_{2}(t)=y_{2}(t)\left[r_{2}(t)+a_{21}^{0}(t) y_{1}(t)+a_{21}^{1}(t) y_{1}(t-\tau)-a_{22}^{0}(t) y_{2}(t)-a_{22}^{1}(t) y_{2}(t-\tau)\right]
\end{array}\right.
$$

Now, we present a useful definition

Definition 1.1 (see [[3] Definition 1.1]) $f(t)$ is called asymptotically periodic function, if $f(t)$ is a continuous function mapping from $R^{+}$to $R$, and satisfies

$$
f(t)=\bar{f}(t)+a(t),
$$

where $\bar{f}(t)$ is a continuous periodic function and $\lim _{t \rightarrow \infty} a(t)=0$.

Now, we present some useful lemmas.

Lemma 2.1 The set $R_{+}^{2}=\left\{\left(x_{1}, x_{2}\right) \mid x_{i}>0, i=1,2\right\}$ is the positively invariant set of system (1)

Proof. We can obtain for $x_{i}(0)=\phi_{i}(0)>0, i=1,2$

$$
\begin{array}{r}
x_{1}(t)=x_{1}(0) \exp \left\{\int_{0}^{t}\left[r_{1}(s)-a_{11}^{1}(s) x_{1}(s-\tau)-a_{11}^{2}(s) x_{1}(s-2 \tau)+a_{12}^{1}(s) x_{2}(s-\tau)\right] \mathrm{d} s\right\} \\
x_{2}(t)=x_{2}(0) \exp \left\{\int_{0}^{t}\left[r_{2}(s)+a_{21}^{0}(s) x_{1}(s)+a_{21}^{1}(s) x_{1}(s-\tau)-a_{22}^{0}(s) x_{2}(s)-a_{22}^{1}(s) x_{2}(s-\tau)\right] \mathrm{d} s\right\}
\end{array}
$$

our results will be discussed in the positively invariant set $R_{+}^{2}$.

Let the set

$$
\Gamma=\left\{\left(x_{1}(t), x_{2}(t)\right) \in R_{+}^{2}: 0<m_{i} \leq x_{i}(t) \leq M_{i}(t)<+\infty(i=1,2), R_{+}=[0,+\infty)\right\}
$$

where $m_{i}, M_{i}(i=1,2)$ are given above (in Introduction).

Lemma 2.2 Assume that $b_{1}^{I L}>0(l=1,2), b_{2}^{L L}>0, b_{22}^{L L}>0$, then system (1) is permanent, where $b_{1}^{l}=a_{11}^{l}(t)-a_{21}^{l-1}(t-\tau), l=1,2$ and $b_{2}^{1}=a_{22}^{0}(t-\tau)-a_{12}^{1}(t-\tau)$.

Lemma 2.3 ([4]) Let $V \in C\left(R_{+} \times S_{H} \times S_{H}, R_{+}\right)$satisfy

1) $a(|x-y|) \leq V(t, x, y) \leq b(|x-y|)$, where $a(r)$ are $b(r)$ are continuously positively increasing functions;

2) $\left|V\left(t, x_{1}, y_{1}\right)-V\left(t, x_{2}, y_{2}\right)\right| \leq l\left(\left|x_{1}-x_{2}\right|+\left|y_{1}-y_{2}\right|\right), \quad l \quad$ is a constant and satisfies $l>0$;

3) There exists continuous function $p(s)$, such that for $s>0, p(s)>s$. And as $P(V(t, \phi(0)))>V(t+\theta, \phi(\theta), \phi(\theta)), \quad \theta \in[-\tau, 0]$, it follows that 
$V_{(2.8)}^{\prime}(t, \phi(0), \phi(0)) \leq-\delta V(t, \phi(0), \phi(0))$, where $\delta$ is a constant and satisfies $\delta>0$.

Furthermore, system (2.7) has a solution $\xi(t)$ for $t \geq t_{0}$ and satisfies $\left\|\xi_{t}\right\| \leq H$. Then system (2.7) has a unique asymptotically periodic solution, which is uniformly asymptotically stable.

Our main purpose is to establish some sufficient conditions on the existence and globally asymptotically stability for the asymptotically periodic solution of the system (1). The method used in this paper is motivated by the work done by Fengying Wei and Wang Ke in [4] and the Lyapunov function method.

\section{Main Results}

Theorem 2.1 Assume that the condition of lemma 2.2 is hold and $a_{11}^{1 L}>a_{21}^{1 M}, a_{22}^{1 L}>a_{12}^{1 M}, W>0$, then there exists a unique asymptotically periodic solution of system (1), which is uniformly asymptotically stable. (W defined in the proof)

Proof. From Lemma 2.2, we know that the solution of system (1) is ultimately bounded. $\Gamma$ is the region of ultimately bounded. We consider the adjoint system (2) of system (1)

For $X(t)=\left(x_{1}(t), x_{2}(t)\right)$ and $Y(t)=\left(y_{1}(t), y_{2}(t)\right)$ are the solution of system (2) in $\Gamma \times \Gamma$. Let $x_{i}^{*}(t)=\ln x_{i}(t), y_{i}^{*}(t)=\ln y_{i}(t),(i=1,2)$. Next we construct a Lyapunov functional as follows:

$$
V(t)=\sum_{i=1}^{2}\left|x_{i}^{*}(t)-y_{i}^{*}(t)\right|
$$

Take $a(r)=b(r)=\sum_{i=1}^{2}\left|x_{i}^{*}(t)-y_{i}^{*}(t)\right|$ and by using the inequality ||$a|-| b|| \leq|a-b|$, we can easily prove 1 ) and 2). To check the condition 3) of Lemma 2.3, we need to calculate upper-right derivative of system (2):

$$
\begin{aligned}
D^{+} V(t)= & D^{+}\left(\left|x_{1}^{*}(t)-y_{1}^{*}(t)\right|+\left|x_{2}^{*}(t)-y_{2}^{*}(t)\right|\right) \\
= & \left(\frac{\dot{x}_{1}}{x_{1}}-\frac{\dot{y}_{1}}{y_{1}}\right) \operatorname{sign}\left(x_{1}(t)-y_{1}(t)\right)+\left(\frac{\dot{x}_{2}}{x_{2}}-\frac{\dot{y}_{2}}{y_{2}}\right) \operatorname{sign}\left(x_{2}(t)-y_{2}(t)\right) \\
\leq & a_{21}^{0 M}\left|x_{1}(t)-y_{1}(t)\right|+\left(-a_{11}^{1 L}+a_{21}^{1 M}\right)\left|x_{1}(t-\tau)-y_{1}(t-\tau)\right| \\
& -a_{21}^{1 L}\left|x_{1}(t-2 \tau)-y_{1}(t-2 \tau)\right|-a_{22}^{0 L}\left|x_{2}(t)-y_{2}(t)\right| \\
& +\left(-a_{22}^{1 L}+a_{12}^{1 M}\right)\left|x_{2}(t-2 \tau)-y_{2}(t-2 \tau)\right| \\
\leq & a_{21}^{0 M}\left|x_{1}(t)-y_{1}(t)\right|-A_{1}\left|x_{1}(t-\tau)-y_{1}(t-\tau)\right| \\
& +a_{22}^{0 M}\left|x_{2}(t)-y_{2}(t)\right|-A_{2}\left|x_{2}(t-\tau)-y_{2}(t-\tau)\right|
\end{aligned}
$$

where $A_{1}=a_{11}^{1 L}-a_{21}^{1 M}, A_{2}=a_{22}^{1 L}-a_{12}^{1 M}$ and we take

$$
\lambda_{1}=\max \left\{a_{21}^{0 M}, a_{22}^{0 M}\right\}, A=\min \left\{A_{1}, A_{2}\right\}
$$

Then we have

$$
\begin{aligned}
D^{+} V(t) \leq & \lambda\left(\left|x_{1}(t)-y_{1}(t)\right|+\left|x_{2}(t)-y_{2}(t)\right|\right) \\
& -A\left(\left|x_{1}(t-\tau)-y_{1}(t-\tau)\right|+\left|x_{2}(t-\tau)-y_{2}(t-\tau)\right|\right)
\end{aligned}
$$


By the following formula:

$$
\begin{aligned}
& \left|x_{i}(t)-y_{i}(t)\right|=\left|\mathrm{e}^{x_{i}^{*}}-\mathrm{e}^{y_{i}^{*}}\right|=\psi_{i}(t) \geq m_{i}\left|x_{i}^{*}-y_{i}^{*}\right|,(i=1,2) \\
& \left|x_{i}(t)-y_{i}(t)\right|=\left|\mathrm{e}^{x_{i}^{*}}-\mathrm{e}^{y_{i}^{*}}\right|=\psi_{i}(t) \leq M_{i}\left|x_{i}^{*}-y_{i}^{*}\right|,(i=1,2)
\end{aligned}
$$

where $\psi_{i}(t)(i=1,2)$ lie in between $x_{i}(t)$ and $y_{i}(t)$ respectively, then $\psi_{i}(t) \in \Gamma$. let $M=\max \left\{M_{1}, M_{2}\right\}, m=\min \left\{m_{1}, m_{2}\right\}$ and if $\lambda_{2} V(t) \leq V(t-\tau)$, where $\lambda_{2}>0$ is a constant, then we have

$$
\begin{aligned}
D^{+} V(t) \leq & \lambda_{1} M\left(\left|x_{1}^{*}-y_{1}^{*}\right|+\left|x_{2}^{*}-y_{2}^{*}\right|\right) \\
& -A m\left(\left|x_{1}^{*}(t-\tau)-y_{1}^{*}(t-\tau)\right|+\left|x_{2}^{*}(t-\tau)-y_{2}^{*}(t-\tau)\right|\right) \\
= & \lambda M V(t)-A m V(t-\tau) \leq-V(t)\left(A m \lambda_{2}-\lambda_{1} M\right):=-W V(t)
\end{aligned}
$$

where $W=\left(A m \lambda_{2}-\lambda_{1} M\right)$.

From the known condition of Theorem 2.1, we obtain that $W>0$, $D^{+} V(t) \leq W V(t)$. Then 3 ) of Lemma 2.3 is satisfied. has system (1) has a unique positive asymptotically periodic solution in domain $\Gamma$, which is uniformly asymptotically stable. The proof is complete.

\section{Conclusions}

In [1] the author's discussed system (1) and derived some sufficient conditions on the permanence of system (1). However, in this paper, based on the permanence of the system (1), we further study system (1) in a asymptotically periodic environment and established conditions on the existence and globally asymptotically stability for the asymptotically periodic solution of the system (1) by using the Lyapunov function method and the method given in Fengying Wei and Wang Ke (Applied Mathematics and Computation 182 (2006) 161 - 165).

We have more interesting topics deserve further investigation, such as the dynamical behaviors of $\mathrm{n}$-species Lotka-Volterra cooperative systems with discrete time delays.

\section{Acknowledgements}

This work was supported by the National Natural Science Foundation of China (Grant No. 11401509).

\section{References}

[1] Nakata, Y. and Muroya, Y. (2010) Permanence for Nonautonomous Lotka-Volterra Cooperative Systems with Delays. Nonlinear Analysis: Real World Applications, 11, 528-534.

[2] Lu, S. (2008) On the Existence of Positive Periodic Solutions to a Lotka Volterra Cooperative Population Model with Multiple Delays. Nonlinear Analysis. Theory, Methods \& Applications, 68, 1746-1753.

[3] Wei, F. and Wang, K. (2006) Asymptotically Periodic Solution of N-Species Cooperation System with Time Delay. Nonlinear Analysis. Real World Applications, 7, 591-596.

[4] Wei, F. and Wang, K. (2006) Global Stability and Asymptotically Periodic Solution 
for Nonautonomous Cooperative Lotka-Volterra Diffusion System. Applied Mathematics and Computation, 182, 161-165.

[5] Wei, F. and Wang, K. (2002) Almost Periodic Solution and Stability for Nonautonmous Cooperative Lotka-Volterra Diffusion System. Songliao Journal (Natural Science Edition), 3.

[6] Liu, C. and Chen, L. (1997) Periodic Solution and Global Stability for Nonautonomous Cooperative Lotka-Volterra Diffusion System. Journal of Lanzhou University (Natural Science), 33, 33-37.

[7] Zhang, J. and Chen, L. (1996) Permanence and Global Stability for Two-Species Co-Operative System with Delays in Two-Patch Environment. Mathematical and Computer Modelling, 23, 17-27.

[8] Chen, F. (2003) Persistence and Global Stability for Nonautonomous Co-Operative System with Diffusion and Time Delay. Acta Scientiarum Naturalium Universitatis Pekinensis, 39, 22-28.

Submit or recommend next manuscript to SCIRP and we will provide best service for you:

Accepting pre-submission inquiries through Email, Facebook, LinkedIn, Twitter, etc. A wide selection of journals (inclusive of 9 subjects, more than 200 journals) Providing 24-hour high-quality service User-friendly online submission system Fair and swift peer-review system Efficient typesetting and proofreading procedure Display of the result of downloads and visits, as well as the number of cited articles Maximum dissemination of your research work

Submit your manuscript at: http://papersubmission.scirp.org/

Or contact ojapps@scirp.org 